\title{
ChemComm
}

\section{Visible light-mediated oxidative decarboxylation of arylacetic acids into benzyl radicals: addition to electron-deficient alkenes by using photoredox catalysts $\dagger$}

Cite this: Chem. Commun., 2013, 49, 7854

Received 13th June 2013, Accepted 4th July 2013

DOI: $10.1039 / c 3 c c 44438 d$

www.rsc.org/chemcomm

Reactions of arylacetic acids bearing an amino group at the para-position in the benzene ring with alkenes in the presence of a catalytic amount of transition metal polypyridyl complexes as photocatalysts under visible light illumination proceed smoothly to give the corresponding benzylated products via oxidative decarboxylation in good to high yields.

Oxidative decarboxylation of carboxylic acids is one of the fundamental and important processes in nature. The mechanism of decarboxylation has been extensively studied in biochemistry. ${ }^{1}$ In organic chemistry, decarboxylation under electrochemical and photochemical conditions provides a useful approach to the formation of alkyl radicals, therefore the decarboxylative dimerization has been found to occur via alkyl radicals as reaction intermediates. $^{2,3}$ The selective bond cleavage at the $\beta$-position with respect to the radical cation center triggered by photoinduced electron transfer is expected to be one of the most useful methods for the decarboxylative formation of alkyl radicals from carboxylic acids. ${ }^{4}$ Especially, it is well known that a single electron oxidation of $\alpha$-amino acids gives $\alpha$-aminoalkyl radicals via decarboxylation, and synthetic use of the $\alpha$-aminoalkyl radicals has been reported (Scheme 1a). ${ }^{5,6}$ In contrast, synthetic utilization of the aminoarylacetic acids, which are the "phenylogue" of the $\alpha$-amino acids, has been quite limited ${ }^{6 a, 7,8}$ in spite of the utility of the generated benzyl radicals bearing an amino group in organic synthesis (Scheme 1b). ${ }^{9}$

Recently we have succeeded in the utilization of $\alpha$-aminoalkyl radicals via fragmentation of radical cations ${ }^{10}$ by a single electron oxidation of amines mediated by photocatalysts. ${ }^{11-13}$ We have envisaged that a single electron transfer using photocatalysts is suitable for oxidation of aminoarylacetic acids to trigger decarboxylation resulting in the corresponding benzyl radicals (Scheme 1b). In fact, we have found radical addition reactions via decarboxylation

Institute of Engineering Innovation, School of Engineering, The University of Tokyo, Yayoi, Bunkyo-ku, Tokyo, 113-8656, Japan. E-mail: ynishiba@sogo.t.u-tokyo.ac.jp; Fax: +81 3-5841-1175; Tel: +81 3-5841-1175

$\dagger$ Electronic supplementary information (ESI) available: Experimental procedures, characterization data for all new compounds. See DOI: 10.1039/c3cc44438d $\ddagger$ Current address: Department of Applied Chemistry, Graduate School of Engineering, Nagoya University, Furo-cho, Chikusa-ku, Nagoya, 464-8603, Japan. E-mail: miyake@apchem.nagoya-u.ac.jp

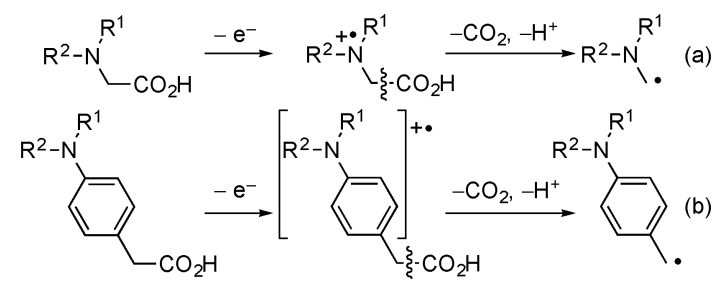

Scheme 1 Oxidative decarboxylation of carboxylic acids bearing an amino group.

of the aminoarylacetic acids to electron-deficient alkenes. Preliminary results are described herein.

At first, we investigated the reaction of 4 -( $N, N$-dimethylamino)phenylacetic acid (1a) with ethyl (E)-2-cyano-3-phenylpropenoate (2a) under various conditions (Table 1 ). When a solution of 1a with 1.1 equiv. of $2 \mathbf{a}$ in the presence of $[\mathbf{4 a}]\left[\mathrm{BF}_{4}\right](1 \mathrm{~mol} \%)$ in acetonitrile (MeCN) was illuminated with a white LED $(14 \mathrm{~W})$ at $25{ }^{\circ} \mathrm{C}$ for $18 \mathrm{~h}$, ethyl 2-cyano-4-(4-( $N, N$-dimethylamino)phenyl)-3-phenylbutanoate (3a) was obtained in $85 \%$ yield (Table 1 , entry 1 ). The reaction using $[\mathbf{4 b}]\left[\mathrm{BF}_{4}\right]$ as a photocatalyst also proceeded smoothly to give $\mathbf{3 a}$ in a similar yield (Table 1, entry 2), while the yield of 3a slightly decreased with the use of $[\mathbf{4 c}]\left[\mathrm{BF}_{4}\right]$ or $\left[\mathrm{Ru}(\mathrm{bpy})_{3}\right]\left[\mathrm{BF}_{4}\right]_{2}$ as a photocatalyst (Table 1, entries 3 and 4). In sharp contrast, when 9,10-dicyanoanthracene (DCA) was used in place of $[\mathbf{4 a}]\left[\mathrm{BF}_{4}\right]$, no formation of $\mathbf{3 a}$ was observed at all (Table 1, entry 5). Use of dimethyl sulfoxide (DMSO) as a solvent in place of MeCN afforded 3a in 81\% yield (Table 1, entry 6). When other polar solvents such as $N, N$-dimethylformamide (DMF) and methanol were used, 3a was obtained in lower yields (Table 1, entries 7 and 8). Using ethyl 4-( $N, N$-dimethylamino)phenylacetate (5a) under similar conditions did not afford 3a at all (Table 1, entry 9). Separately, we confirmed that no formation of $\mathbf{3} \mathbf{a}$ was observed in the absence of visible light or a photocatalyst. In the previously reported oxidative decarboxylation, ${ }^{2,3,7}$ the homo-coupling of benzyl radicals easily occurred to give the corresponding bibenzyl (6), while no formation of $\mathbf{6}$ was observed in all cases presented in Table 1 . This result indicates that a visible lightmediated electron transfer using photocatalysts is favorable for addition of benzyl radicals derived from phenylacetic acids to alkenes.

Next, we investigated reactions of a variety of arylacetic acids (1) with 2a (Table 2). The reaction of phenylacetic acid bearing an $\mathrm{N}, \mathrm{N}$-diethylamino moiety at the para-position of the benzene ring 
Table 1 Photochemical reactions of 4-(N,N-dimethylamino)phenylacetic acid (1a) with ethyl (E)-2-cyano-3-phenylpropenoate (2a) ${ }^{a}$

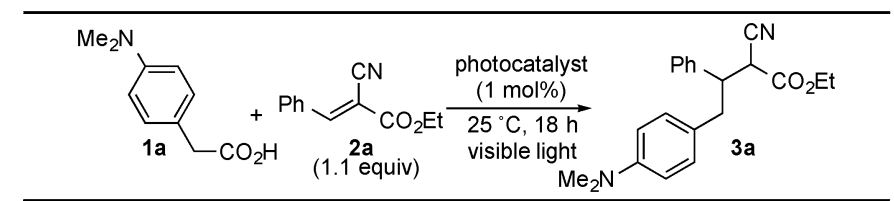

\begin{tabular}{llll}
\hline Entry & Photocatalyst & Solvent & ${\text { Yield of } \mathbf{3 a}^{b}(\%)}^{(\%)}$ \\
\hline 1 & {$[\mathbf{4 a}]\left[\mathrm{BF}_{4}\right]$} & MeCN & 85 \\
2 & {$[\mathbf{4 b}]\left[\mathrm{BF}_{4}\right]$} & MeCN & 84 \\
3 & {$[\mathbf{4 c}]\left[\mathrm{BF}_{4}\right]$} & MeCN & 70 \\
4 & {$\left[\mathrm{Ru}\left(\mathrm{bpy}_{3}\right]\left[\mathrm{BF}_{4}\right]_{2}\right.$} & MeCN & 68 \\
5 & $\mathrm{DCA}$ & MeCN & 0 \\
6 & {$[\mathbf{4 a}]\left[\mathrm{BF}_{4}\right]$} & DMSO & 81 \\
7 & {$[\mathbf{4 a}]\left[\mathrm{BF}_{4}\right]$} & DMF & 76 \\
8 & {$[\mathbf{4 a}]\left[\mathrm{BF}_{4}\right]$} & MeOH & 57 \\
$9^{c}$ & {$[\mathbf{4 a}]\left[\mathrm{BF}_{4}\right]$} & MeCN & 0
\end{tabular}
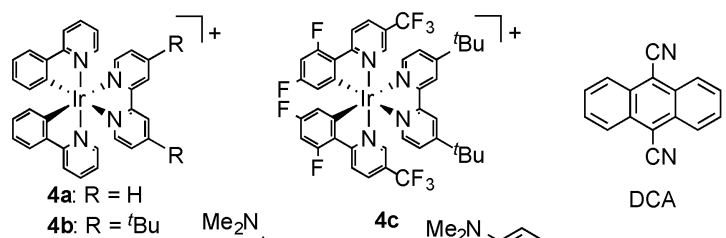

$4 \mathrm{~b}: \mathrm{R}={ }^{t} \mathrm{~B}$
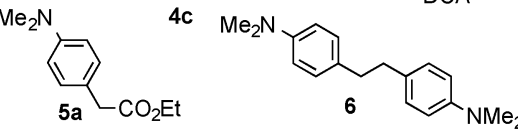

${ }^{a}$ All reactions of $1 \mathrm{a}(0.25 \mathrm{mmol})$ with $2 \mathrm{a}(0.275 \mathrm{mmol})$ were carried out in the presence of a photocatalyst $(0.0025 \mathrm{mmol})$ in solvent $(2.5 \mathrm{~mL})$ under $14 \mathrm{~W}$ white LED illumination at $25{ }^{\circ} \mathrm{C}$ for $18 \mathrm{~h} .{ }^{b}$ Isolated yield. ${ }^{c} \mathbf{5 a}$ was used in place of $\mathbf{1 a}$.

Table 2 Photochemical reactions of arylacetic acids (1) with $2 a^{a}$

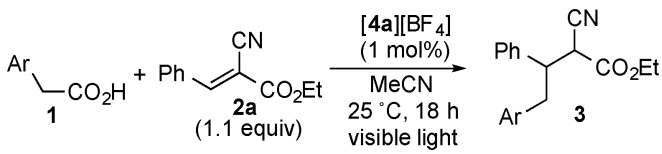

\begin{tabular}{|c|c|c|}
\hline Entry & Arylacetic acid (1) & Yield of $3^{b}(\%)$ \\
\hline 1 & $\mathrm{Ar}=4-\mathrm{Et}_{2} \mathrm{~N}-\mathrm{C}_{6} \mathrm{H}_{4}(\mathbf{1 b})$ & $84(3 \mathbf{b})$ \\
\hline 2 & $\mathrm{Ar}=4-\mathrm{PhMeN}-\mathrm{C}_{6} \mathrm{H}_{4}(\mathbf{1 c})$ & $89(3 c)$ \\
\hline 3 & $\mathrm{Ar}=4-(N$-morpholino $)-\mathrm{C}_{6} \mathrm{H}_{4}(\mathbf{1 d})$ & $96(3 d)$ \\
\hline 4 & $\mathrm{Ar}=4-(N$-pyrrolidino $)-\mathrm{C}_{6} \mathrm{H}_{4}(\mathbf{1 e})$ & $74(3 \mathrm{e})$ \\
\hline 5 & $\mathrm{Ar}=4-\mathrm{BnHN}-\mathrm{C}_{6} \mathrm{H}_{4}(\mathbf{1 f})$ & $81(3 f)$ \\
\hline $6^{c}$ & $\mathrm{Ar}=4-\mathrm{H}_{2} \mathrm{~N}-\mathrm{C}_{6} \mathrm{H}_{4}(\mathbf{1 g})$ & $87(3 g)$ \\
\hline 7 & $\mathrm{Ar}=4-(N$-morpholino $)-1$-naphthyl (1h) & $61(3 \mathrm{~h})$ \\
\hline
\end{tabular}

${ }^{a}$ All reactions of $\mathbf{1}(0.25 \mathrm{mmol})$ with $2 \mathrm{a}(0.275 \mathrm{mmol})$ were carried out in the presence of $[4 \mathrm{aa}]\left[\mathrm{BF}_{4}\right](0.0025 \mathrm{mmol})$ in $\mathrm{MeCN}(2.5 \mathrm{~mL})$ under $14 \mathrm{~W}$ white LED illumination at $25{ }^{\circ} \mathrm{C}$ for $18 \mathrm{~h} .{ }^{b}$ Isolated yield. ${ }^{c}$ DMSO was used in place of MeCN.

(1b) proceeded to give $\mathbf{3 b}$ in $84 \%$ yield (Table 2, entry 1 ). Other phenylacetic acids bearing a variety of tertiary amino groups such as $N$-methyl- $N$-phenylamino, $N$-morpholino, and $N$-pyrrolidino moieties at the para-position of the benzene ring were also applicable, giving the corresponding products (3c-3e) in high yields (Table 2, entries 2-4). Reactions of phenylacetic acids bearing secondary (1f) and primary amino (1g) groups also took place smoothly to give $3 \mathbf{f}$ and $3 \mathrm{~g}$ in $81 \%$ and $87 \%$ yields, respectively (Table 2, entries 5 and 6 ). When the acetic acid bearing a 4 -( $N$-morpholino)-1-naphthyl (1h) group was used, $3 \mathbf{h}$ was obtained in a good yield (Table 2 , entry 7 ).

Other reactions of $\mathbf{1 d}$ or $\mathbf{1 g}$ with a variety of alkenes (2) were also examined by using $[\mathbf{4 a}]\left[\mathrm{BF}_{4}\right]$ as a photocatalyst (Table 3 ).
Table 3 Photochemical reactions of arylacetic acids (1d or $1 \mathbf{g}$ ) with alkenes $(2)^{a}$

\begin{tabular}{|c|c|c|c|c|}
\hline & $\mathrm{R}^{2} \cdot \mathrm{N}^{\mathrm{R}^{1}}$ & $+\mathrm{R}^{3} \underbrace{\mathrm{E}^{1}}_{\mathrm{O}_{2} \mathrm{H}} \mathrm{E}^{2}$ & 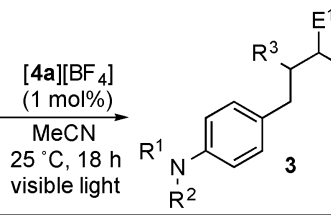 & \\
\hline Entry & $\begin{array}{l}\text { Arylacetic } \\
\text { acid (1) }\end{array}$ & Alkene (2) & & $\begin{array}{l}\text { Yield of } \\
3^{b}(\%)\end{array}$ \\
\hline 1 & 1d & $\mathrm{R}^{3}=4-\mathrm{MeOC}_{6} \mathrm{H}$ & ${ }_{4}, \mathrm{E}^{1}=\mathrm{CN}, \mathrm{E}^{2}=\mathrm{CO}_{2} \mathrm{Et}(2 \mathrm{~b})$ & $74(3 \mathbf{i})$ \\
\hline 2 & 1d & $\mathrm{R}^{3}=4-\mathrm{MeC}_{6} \mathrm{H}_{4}$, & $\mathrm{E}^{1}=\mathrm{CN}, \mathrm{E}^{2}=\mathrm{CO}_{2} \mathrm{Et}(2 \mathrm{c})$ & $93(\mathbf{3} \mathbf{j})$ \\
\hline 3 & 1d & $\mathrm{R}^{3}=4-\mathrm{PhC}_{6} \mathrm{H}_{4}$ & $\mathrm{E}^{1}=\mathrm{CN}, \mathrm{E}^{2}=\mathrm{CO}_{2} \mathrm{Et}(2 \mathrm{~d})$ & $66(3 \mathbf{k})$ \\
\hline 4 & 1d & $\mathrm{R}^{3}=4-\mathrm{ClC}_{6} \mathrm{H}_{4}, \mathrm{I}$ & $\mathrm{E}^{1}=\mathrm{CN}, \mathrm{E}^{2}=\mathrm{CO}_{2} \mathrm{Et}(2 \mathrm{e})$ & $52(31)$ \\
\hline 5 & 1d & $\mathrm{R}^{3}=\mathrm{PhCH}_{2} \mathrm{CH}_{2}$ & $, \mathrm{E}^{1}=\mathrm{CN}, \mathrm{E}^{2}=\mathrm{CO}_{2} \mathrm{Et}(\mathbf{2 f})$ & $80(3 \mathrm{~m})$ \\
\hline 6 & 1d & $\mathrm{R}^{3}={ }^{\mathrm{i}} \mathrm{Pr}, \mathrm{E}^{1}=\mathrm{CI}$ & $\mathrm{N}, \mathrm{E}^{2}=\mathrm{CO}_{2} \mathrm{Et}(2 \mathrm{~g})$ & $51(3 n)$ \\
\hline 7 & 1d & $\mathrm{R}^{3}=\mathrm{Ph}, \mathrm{E}^{1}=\mathrm{E}^{2}$ & $=\mathrm{CN}(2 \mathbf{h})$ & $70(30)$ \\
\hline 8 & 1d & $\mathrm{R}^{3}=\mathrm{Ph}, \mathrm{E}^{1}=\mathrm{E}^{2}$ & $=\mathrm{CO}_{2} \mathrm{Et}(2 \mathbf{i})$ & $16(3 p)$ \\
\hline $9^{c}$ & $1 \mathrm{~g}$ & $\mathrm{R}^{3}=4-\mathrm{MeC}_{6} \mathrm{H}_{4}$, & $\mathrm{E}^{1}=\mathrm{CN}, \mathrm{E}^{2}=\mathrm{CO}_{2} \mathrm{Et}(2 \mathrm{c})$ & $90(3 q)$ \\
\hline $10^{c}$ & 19 & $\mathrm{R}^{3}=\mathrm{PhCH}_{2} \mathrm{CH}_{2}$ & $, \mathrm{E}^{1}=\mathrm{CN}, \mathrm{E}^{2}=\mathrm{CO}_{2} \mathrm{Et}(\mathbf{2 f})$ & $51(3 r)$ \\
\hline
\end{tabular}

${ }^{a}$ All reactions of $1(0.25 \mathrm{mmol})$ with $2 \mathrm{a}(0.275 \mathrm{mmol})$ were carried out in the presence of $[4 \mathbf{a}]\left[\mathrm{BF}_{4}\right](0.0025 \mathrm{mmol})$ in $\mathrm{MeCN}(2.5 \mathrm{~mL})$ under $14 \mathrm{~W}$ white LED illumination at $25{ }^{\circ} \mathrm{C}$ for $18 \mathrm{~h} .{ }^{b}$ Isolated yield. ${ }^{c}$ DMSO was used in place of MeCN.

Introduction of substituents such as methoxy, methyl, phenyl, and chloro at the para-position of the benzene ring of $\mathbf{2 a}$ is successful in giving the corresponding products $(\mathbf{3 i}-\mathbf{3 l})$ in good to high yields (Table 3, entries 1-4). Alkenes bearing phenylethyl and iso-propyl groups at the $\beta$-position were applied to give $3 \mathbf{m}$ and $3 \mathbf{n}$ in $80 \%$ and $51 \%$ yields, respectively (Table 3 , entries 5 and 6 ). The reaction of $\mathbf{1 d}$ with benzylidenemalononitrile ( $\mathbf{2 h}$ ) proceeded smoothly to give $\mathbf{3 0}$ in $70 \%$ yield (Table 3 , entry 7 ). However, a lower yield of $3 \mathbf{p}$ was obtained when diethyl benzylidenemalonate (2i) was used as a substrate (Table 3, entry 8). The arylacetic acid bearing an amino group (1g) was also transformed efficiently into $\mathbf{3 q}$ and $3 \mathbf{r}$ in $90 \%$ and $51 \%$ yields (Table 3, entries 9 and 10).

To investigate the effect of the position of an amino group, we carried out reactions of phenylacetic acids bearing a morpholino group at the para-, meta- and ortho-positions of the benzene ring (1d, $1 \mathbf{d}^{\prime}$ and $\mathbf{1 d}^{\prime \prime}$ ) with $2 \mathrm{a}$ under similar conditions (Scheme 2). In sharp contrast to the reaction of $\mathbf{1 d}$, when $\mathbf{1} \mathbf{d}^{\prime}$ and $\mathbf{1} \mathbf{d}^{\prime \prime}$ were used as substrates, no formation of the corresponding products $\mathbf{3} \mathbf{d}^{\prime}$ and $\mathbf{3} \mathbf{d}^{\prime \prime}$ was observed at all. Furthermore, in order to explore the origin of this reactivity, we also investigated fluorescence quenching studies of $\mathbf{4 a}$ in the presence of $\mathbf{1 d}$, $\mathbf{1} \mathbf{d}^{\prime}$ or $\mathbf{1} \mathbf{d}^{\prime \prime}$ in $\mathrm{MeCN}$. The rate constants for $\mathbf{1 d}$ and $\mathbf{1} \mathbf{d}^{\prime}$ were estimated to be $2.86 \times 10^{8} \mathrm{M}^{-1} \mathrm{~s}^{-1}$ and $6.78 \times 10^{7} \mathrm{M}^{-1} \mathrm{~s}^{-1}$ respectively, by using the Stern-Volmer plot, while no quenching of $4 \mathbf{a}$ by $1 \mathbf{d}^{\prime \prime}$ occurred at all. From these results, it is revealed that oxidation of $\mathbf{1} \mathbf{d}^{\prime}$ certainly occurred but sequential decarboxylation hardly proceeded. It is reported that the unpaired electron spin density at the para-position in the benzene ring

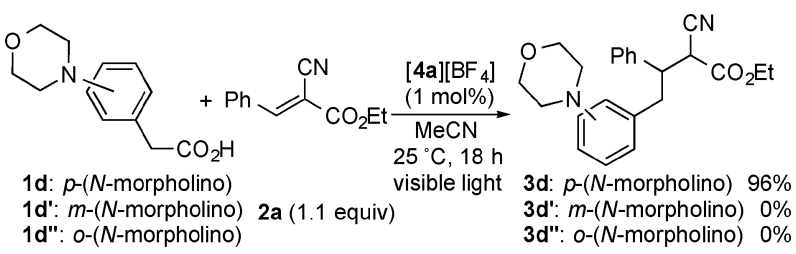

Scheme 2 Effect of the position of the amino group on reactions of $\mathbf{1 d}, \mathbf{1} \mathbf{d}^{\prime}$, and $1 d^{\prime \prime}$ with $2 a$. 


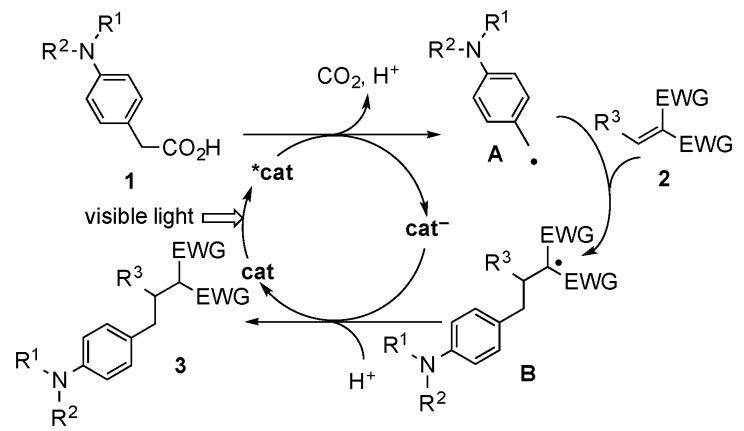

Scheme 3 Plausible reaction pathway.

of the one-electron oxidized aniline is much higher than that at the meta-position. ${ }^{14}$ The radical character in the benzene ring of the oneelectron oxidized $\mathbf{1 d}$ and $\mathbf{1} \mathbf{d}^{\prime}$ is expected to have a great effect on the desirable decarboxylation. In the case of $\mathbf{1} \mathbf{d}^{\prime}$, the radical character of the carbon atom at the meta-position with respect to the amino group (at the $\beta$-position with respect to the carboxyl group) of the oxidized $\mathbf{1 d}^{\prime}$ is too small to induce efficient decarboxylation. On the other hand, Stern-Volmer analysis clearly indicates that oxidation of $\mathbf{1 d}^{\prime \prime}$ under photoirradiation occurs scarcely although the spin population at the ortho-position is also known to be similar to that at the para-position. This is probably because an intramolecular hydrogen bonding between the amino group and carboxylic acid in $\mathbf{1 d}^{\prime \prime}$ inhibits the electron transfer oxidation. ${ }^{15}$ In addition, we confirmed that no reaction of 4-methoxyphenylacetic acid (1i) under similar conditions occurred at all. These facts clearly indicate that decarboxylation triggered by a single electron oxidation of the amino group at the para-position is one of the key steps to promote these transformations.

A plausible reaction pathway is shown in Scheme 3. First, a single electron oxidation of aminoarylacetic acid (1) by an excited photocatalyst (*cat) and sequential decarboxylation occur to give the benzyl radical (A) and the reduced form of the photocatalyst $\left(\mathbf{c a t}^{-}\right){ }^{4,8}$ Addition of $\mathbf{A}$ to 2 results in the formation of the radical intermediate (B). Finally, reduction of $\mathbf{B}$ by $\mathbf{c a t}^{-}$and subsequent protonation proceed to give the product (3) accompanied by regeneration of the photocatalyst (cat). The reduction of $\mathbf{B}$ by the reduced form of an iridium catalyst $\left.\left(\operatorname{Ir}(\mathrm{ppy})_{2}(\mathrm{bpy})\right]^{0}\right)$ is feasible according to the literature redox potentials. ${ }^{16,17}$ The quantum yield in the reaction of 19 with 2 a was estimated to be 0.21 , which is less than 1 and is in the common range of molecular transformations via photoinduced electron transfer with transition metal polypyridyl complexes. ${ }^{10}$ This result suggests that the contribution of a photo independent process including a radical chain process is negligible in the present system. ${ }^{10}$ The pathway shown in Scheme 3 is similar to that described in our previous report on the addition of $\alpha$-aminoalkyl radicals to electron-deficient alkenes. ${ }^{10 c}$ On the other hand, considering the redox potential of cyanoesters $2,{ }^{16}$ the reaction pathway via reduction of 2 by the excited photocatalyst ${ }^{17}$ and subsequent radical-radical coupling is also possible. ${ }^{10 a, 18}$

In summary, we have succeeded in the visible light-mediated synthetic utilization of benzyl radicals formed by oxidation and subsequent decarboxylation of arylacetic acids. This reaction system is applicable for addition of a variety of benzyl radicals bearing an amino group at the para-position in the benzene ring to electrondeficient alkenes. A number of transformations using alkyl radicals from alkyl halides as reaction intermediates have been reported until now, where alkyl halides are known to be promising precursors for generation of alkyl radicals. ${ }^{9}$ However, examples for preparation of alkyl halides bearing amino groups in a single molecule are limited due to undesirable reactions including $N$-alkylation reactions. ${ }^{19} \mathrm{We}$ believe that the method described here provides an alternative route for generation of benzyl radicals bearing an amino group.

\section{Notes and references}

1 (a) T. Li, L. Huo, C. Pulley and A. Liu, Bioorg. Chem., 2012, 43, 2; (b) G.-G. Chang and L. Tong, Biochemistry, 2003, 42, 12721; (c) W. W. Cleland, Acc. Chem. Res., 1999, 32, 862.

2 A. K. Vijh and B. E. Conway, Chem. Rev., 1967, 67, 623.

3 D. Budac and P. Wan, J. Photochem. Photobiol., A, 1992, 67, 135.

4 (a) E. Baciocchi, M. Bietti and O. Lanzalunga, J. Phys. Org. Chem., 2006, 19, 467; (b) E. Baciocchi, M. Bietti and O. Lanzalunga, Acc. Chem. Res., 2000, 33, 243.

5 For reviews, see: $(a)$ D. W. Cho, U. C. Yoon and P. S. Mariano, Acc. Chem. Res., 2011, 44, 204; (b) U. C. Yoon and P. S. Mariano, Acc. Chem. Res., 1992, 25, 233.

6 (a) Y. Yoshimi, K. Kobayashi, H. Kamakura, K. Nishikawa, Y. Haga, K. Maeda, T. Morita, T. Itou, Y. Okada and M. Hatanaka, Tetrahedron Lett., 2010, 51, 2332; (b) A. G. Griesbeck, T. Heinrich, M. Oelgemöller, J. Lex and A. Molis, J. Am. Chem. Soc., 2002, 124, 10972; (c) A. G. Griesbeck, T. Heinrich, M. Oelgemöller, A. Molis and A. Heidtmann, Helv. Chim. Acta, 2002, 85, 4561; (d) Z. Su, P. S. Mariano, D. E. Falvey, U. C. Yoon and S. W. Oh, J. Am. Chem. Soc., 1998, 120, 10676.

7 L. Cermenati, M. Mella and A. Albini, Tetrahedron, 1998, 54, 2575.

8 M. A. Smitha, E. Prasad and K. R. Gopidas, J. Am. Chem. Soc., 2001, 123, 1159.

9 (a) For reviews see: P. Renaud, in Radicals in Organic Synthesis, ed. P. Renaud, M. P. Sibi, Wiley-VCH, Weinheim, 2001; (b) G. J. Rowlands, Tetrahedron, 2010, 66, 1593; (c) I. Ryu, N. Sonoda and D. P. Curran, Chem. Rev., 1996, 96, 177; (d) C. P. Jasperse, D. P. Curran and T. L. Fevig, Chem. Rev., 1991, 91, 1237.

10 (a) Y. Miyake, K. Nakajima and Y. Nishibayashi, Chem.-Eur. J., 2012, 18, 16473; (b) Y. Miyake, Y. Ashida, K. Nakajima and Y. Nishibayashi, Chem. Commun., 2012, 48, 6966; (c) Y. Miyake, K. Nakajima and Y. Nishibayashi, J. Am. Chem. Soc., 2012, 134, 3338. 11 (a) L. R. Espelt, E. M. Wiensch and T. P. Yoon, J. Org. Chem., 2013, 78, 4107; (b) S. Zhu, A. Das, L. Bui, H. Zhou, D. P. Curran and M. Rueping, J. Am. Chem. Soc., 2013, 135, 1823; (c) P. Kohls, D. Jadhav, G. Pandey and O. Reiser, Org. Lett., 2012, 14, 672; (d) A. McNally, C. K. Prier and D. W. C. MacMillan, Science, 2011, 334, 1114.

12 M. T. Pirnot, D. A. Rankic, D. B. C. Martin and D. W. C. MacMillan, Science, 2013, 339, 1593.

13 For recent reviews, see: $(a)$ C. K. Prier, D. A. Rankic and D. W. C. MacMillan, Chem. Rev., 2013, 113, 5322, DOI: 10.1021/cr300503r; (b) L. Shi and W. Xia, Chem. Soc. Rev., 2012, 41, 7687; (c) J. Xuan and W.-J. Xiao, Angew. Chem., Int. Ed., 2012, 51, 6828; (d) M. A. Ischay and T. P. Yoon, Eur. J. Org. Chem., 2012, 3359; (e) S. Maity and N. Zheng, Synlett, 2012, 1851; $(f)$ J. W. Tucker and C. R. J. Stephenson, J. Org. Chem., 2012, 77, 1617.

14 G. D’Aprano, E. Proynov, M. Lebœuf, M. Leclerc and D. R. Salahub, J. Am. Chem. Soc., 1996, 118, 9736.

15 (a) D. A. Smith and S. Vijayakumar, Tetrahedron Lett., 1991, 32, 3617; (b) X. Li, Y.-D. Wu and D. Yang, Acc. Chem. Res., 2008, 41, 1428; (c) X.-J. Liao, W. Guo and S.-H. Xu, Acta Crystallogr., Sect. E, 2011, 67, o1732; (d) R. K. Castellano, Y. Li, E. A. Homan, A. J. Lampkins, I. V. Marín and K. A. Abboud, Eur. J. Org. Chem., 2012, 4483.

16 X.-Q. Zhu, M. Zhang, Q.-Y. Liu, X.-X. Wang, J.-Y. Zhang and J.-P. Cheng, Angew. Chem., Int. Ed., 2006, 45, 3954.

17 F. O. Garces, K. A. King and R. J. Watts, Inorg. Chem., 1988, 27, 3464. 18 See ESI $\dagger$ for experimental details.

19 Examples for preparation of 4-aminobenzyl bromides: $(a)$ G. Wang, X. Zhang, J. Geng, K. Li, D. Ding, K.-Y. Pu, L. Cai, Y.-H. Lai and B. Liu, Chem.-Eur. J., 2012, 18, 9705; (b) J.-P. Leclerc, J.-P. Falgueyret, M. Girardin, J. Guay, S. Guiral, Z. Huang, C. S. Li, R. Oballa, Y. K. Ramtohul, K. Skorey, P. Tawa, H. Wang and L. Zhang, Bioorg. Med. Chem. Lett., 2011, 21, 6505; (c) H. Enomoto, Y. Morikawa, Y. Miyake, F. Tsuji, M. Mizuchi, H. Suhara, K. Fujimura, M. Horiuchi and M. Ban, Bioorg. Med. Chem. Lett., 2009, 19, 442. 